NBER WORKING PAPER SERIES

\title{
EDUCATION FINANCE REFORM AND \\ INVESTMENT IN HUMAN CAPITAL: \\ LESSONS FROM CALIFORNIA
}

\author{
Raquel Fernandez \\ Richard Rogerson
}

Working Paper 5369

\section{NATIONAL BUREAU OF ECONOMIC RESEARCH \\ 1050 Massachusetts Avenue \\ Cambridge, MA 02138 \\ November 1995}

We thank Kevin Lang, Jonathan Portes, Ed Prescott and Mark Schweitzer for comments as well as seminar participants at the Bank of Canada, Queen's University, Federal Reserve Bank of Atlanta, and the Federal Reserve Bank of Cleveland. This paper is part of NBER's research programs in International Finance and Macroeconomics, and Public Economics. Any opinions expressed are those of the authors and not those of the National Bureau of Economic Research.

(C) 1995 by Raquel Fernandez and Richard Rogerson. All rights reserved. Short sections of text, not to exceed two paragraphs, may be quoted without explicit permission provided that full credit, including $\odot$ notice, is given to the source. 


\title{
EDUCATION FINANCE REFORM AND INVESTMENT IN HUMAN CAPITAL: LESSONS FROM CALIFORNIA
}

\begin{abstract}
This paper examines the effect of different education financing systems on the level and distribution of resources devoted to public education. We focus on California, which in the 1970 's moved from a system of mixed local and state financing to one of effectively pure state finance and subsequently saw its funding of public education fall between ten and fifteen percent relative to the rest of the US. We show that a simple political economy model of public finance can account for the bulk of this drop. We find that while the distribution of spending became more equal, this was mainly at the cost of a large reduction in spending in the wealthier communities with little increase for the poorer districts. Our model implies that there is no simple trade-off between equity and resources; we show that if California had moved to the opposite extreme and abolished state aid altogether, funding for public education would also have dropped by almost ten percent.
\end{abstract}

Raquel Fernandez

Department of Economics

New York University

New York, NY 10003

and NBER
Richard Rogerson

Department of Economics

University of Minnesota

Minneapolis, MN 55455 


\section{Introduction}

A large volume of work emphasizes the importance of physical and human capital accumulation for the process of economic growth. This has generated an accompanying literature that analyzes how various policies affect investment in physical and human capital. The main concern of this literature is how the taxation of income from these sources affects accumulation and growth. A distinctive feature of human capital accumulation, however, is the significant role played by government in its financing. The focus of this paper, therefore, is on how different systems of financing education affect both the level and distribution of human capital investment.

The motivation for this undertaking is straightforward. In the US, both the fraction of personal income devoted to public elementary and secondary school and the systems used to finance public education vary widely across states. As illustrated in Table 1.1 below, the investment share for some states is nearly double that of others, a ratio similar to the relative investment shares found for physical investment in a cross section of countries. $^{1}$ It is natural, therefore, to ask to what extent differences in financing systems can account for these differences in human capital investment shares. ${ }^{2}$ while this question can be approached in a variety of

${ }^{1}$ We note that these differences in investment shares do correspond to real differences in resources. For example, the ratio of pupils in average daily attendance to number of teachers is 23.0 in California, 17.8 in Tennessee, 12.7 in Vermont, 14.6 in Wyoming and 12.3 in New Jersey.

${ }^{2}$ see Inman (1978) for a normative analysis of several alternative education finance systems. 
manners, we choose to examine it from a political economy perspective of public finance. 3

Table 1.1

Share of Personal Income Devoted to Public Primary and Secondary Education

(Current Expenditures)

Tennessee $\quad .033$

Illinois $\quad .034$

Hawaii $\quad .036$

California .036

New Jersey .049

Maine $\quad .053$

Vermont $\quad .058$

wyoming $\quad .062$

Source: Statistical Abstract of the US, 1992

We conduct our analysis in a version of the Tiebout model, which is the standard model of local public finance. In our model there are a large number of families with preferences defined over consumption and the quality of education obtained by their children. Families are distinguished by income and, a la Tiebout (1956), we assume that families are sorted perfectly by income across communities so that a given community contains only families with the same income. A school financing system is a set of rules which governs how resources are allocated to education and the extent to which resources are redistributed across communities. For a given financing system, we assume that its parameters are chosen by a process of majority vote.

Though the framework we employ can be used to analyze diverse changes in education financing systems, our analysis focuses on the experience of California since this case has received considerable attention. Two events from the 1970's, the serrano decision, which ruled California's education

${ }^{3}$ Krusell, Quadrini, and Rios-Rull (1995) likewise use a political economy approach to examine tax systems and Persson and Tabellini (1993) to examine federalist structures. 
finance system unconstitutional, and Proposition 13, which severely limited local property tax revenues, lead to a major restructuring of California's public education finance system. The result of these two events was to move California from a foundation system in which local expenditures supplemented expenditure levels guaranteed by the state to one in which effectively all financing is done at the state level. What makes the California experience so noteworthy is that subsequent to these changes, California's share of personal income going to public education fell by more than ten percent relative to the US average.

Using the model sketched above, we illustrate through some examples that absent any restriction on preferences the range of the associated effects is extremely large; simulations of a California-style reform can lead to decreases in expenditures as low as two percent and as large as forty percent. This outcome is perhaps not too surprising--a similar situation occurs, for example, if one asks how redistributive labor income taxation affects labor supply. In that context, as in others, long-run observations provide restrictions on preferences which have proven to be very useful in applied work. We follow a similar procedure here and find that a simple restriction implied by longer-run observations greatly restricts the range of outcomes predicted by the model. In particular, we constrain preferences to satisfy the requirement that expenditures on education grow at the same rate as personal income when the income distribution is scaled proportionately. ${ }^{4}$ Imposing the above restriction, we obtain the result that California's reform reduces educational expenditures by about $10 \%$, which suggests that our simple political economy view of public finance is able to account for the

${ }^{4}$ This type of "balanced growth" restriction is also standard in the growth literature. 
bulk of California's drop in educational expenditures. Our analysis also generates some interesting results concerning the relationship between equity of educational expenditures and the total amount of resources devoted to education. While we find that California's move from a foundation system to a state system achieved greater equity, our analysis suggests that this was accomplished almost entirely by decreasing educational expenditures in wealthier districts--poor families benefited very little.

The above, however, should not be taken to imply a simple trade-off between equity and total resources, with more local systems delivering greater inequality but more resources and the opposite for more centralized systems. For example, our analysis suggests that had California moved from a foundation system to a pure local system (i.e., one with no redistribution), total expenditures would also have decreased on the order of ten percent, despite a doubling of inequality as measured by the coefficient of variation of per student spending.

The remainder of the paper is organized as follows. Section 2 provides an overview of education finance developments in California, and documents the changes that took place over the last twenty-five years. Section 3 lays out the theoretical structure and derives some analytic results concerning the effect of California's reform. Section 4 carries out the numerical work and examines who won and who lost as a result of the reform. Section 5 contrasts our explanation of California's decline in education spending with some alternative interpretations. Section 6 concludes.

\author{
2. Some Background \\ Prior to serrano I, public school financing in California was \\ accomplished through a foundation system. This system, established in 1947 ,
}


prescribed a minimum property tax rate and guaranteed each district that taxed at this rate the difference between the foundation amount and its property tax revenues. Districts that generated revenue that surpassed the foundation amount were not given any foundation aid. In addition to local property taxes and foundation aid, education was financed by categorical aid distributed by the state and federal system and by basic aid of $\$ 120$ per average daily attendance (ADA) assured by the state. ${ }^{5}$ As of 1970 , local property taxes constituted slightly over $50 \%$ of school revenue, and despite the fact that the state played a role in equalizing expenditures beyond what would exist in a pure local system with no redistribution, California possessed one of the least equal education expenditure systems in the country. ${ }^{6}$

The above was the prevailing state of affairs when in August 1971 the California supreme Court ruled in the case of Serrano v. Priest that the finance system "discriminates against the poor because it makes the quality of a child's education a function of the wealth of his parents and neighbors." 7 Between 1972 and the present, the system of education finance was radically modified.

The history of school finance reform in California over the last twenty five years is too complex and lengthy to attempt a review of it here. Its main features, however, were established early on and it can be conveniently summarized by listing its main components prior to the passage of Proposition 13 in June 1978 and the effect of the latter. The principal components of the

${ }^{5}$ The latter resulted from a constitutional requirement. For a brief history of this see picus (1991).

${ }^{6}$ See Brown, L. et al (1978).

${ }^{7}$ While some low income districts had high or average spending, such as the large urban districts, the correlation between the local tax base and spending per student was .64 in 1975 (see Downes (1992)). 
various bills passed were i) foundation program increases, ii) revenue limits, iii) reduction in permissive overrides, and iv) categorical programs. 8 Revenue limits were introduced in response to the initial serrano ruling as a way to help reduce the disparity in spending between districts. It ensured that if a district's assessed valuation grew at a faster rate than its revenue limit, it had to reduce its tax rate. The revenue limit for these districts was allowed to adjust upwards by at most $6 \%$ a year. On the other hand, districts with revenues below the foundation amounts were allowed to increase their revenue limits by $15 \%$ a year. These limits, however, were allowed to be overridden by the voters of a district, but no longer by the school boards. In addition to the foundation amount, funds were also appropriated for different categorical programs designed to aid districts with large percentages of lower-income families.

During this same period in which further reforms were being considered in response to court rulings, Californian voters approved Proposition 13.9 The latter prohibited state and local governments from passing new property taxes, limited the tax rate on all property to 18 of its $1975-76$ assessed value allowing reassessments only if the property were sold, and required a two-thirds vote of the people residing in a jurisdiction to impose any special tax and two-thirds of the legislature for any change in state taxes. ${ }^{10}$ This, combined with the legacy of Serrano, had the effect in practice of removing

\footnotetext{
${ }^{8}$ The first major reform bill (SB90) took effect in fiscal year 1973-74. The second major reform bill (AB65) was to take effect in fiscal year 1978-79 but was made obsolete by the passage of Proposition 13.

${ }^{9}$ One such reform would have been a move to a system of power equalization which would have guaranteed all districts the same tax base but allowed local variation in tax rates and hence expenditure levels. See picus (1991) for an account.

${ }^{10}$ See O'Sullivan et al. (1995) for a comprehensive review of proposition 13.
} 
the decision for how much revenue should be allocated to education from the hands of the individual district to those of the state. Revenue limits were kept in place (now adjusted solely by the statutory Cost of Living Adjustment and the type-unified, primary, or secondary--of district) and the revenue limit aid again determined by the difference between the revenue limit and property tax collections. 11

Put briefly, the effect of Serrano and Proposition 13 was to change the financing system from a foundation system in which the state redistributed educational resources across districts but which allowed individual districts to increase spending by increasing their tax rate if desired, to essentially a state system which left the amount of spending up to the state and guaranteed virtually equal spending (per student) across districts. 12

We next turn to a review of what we believe to be the salient features of the California reform. Table 2.1 provides some information about the system in place prior to the reforms.

${ }^{11}$ As before, each district received $\$ 120$ per ADA independently of its need for revenue limit aid.

12 It should be noted that official statistics indicate that roughly twenty-five percent of total spending comes from local sources. Local tax rates, however, are forcibly low and the same across localities. Therefore, revenues raised in this fashion are all inframarginal with respect to the revenue limits, and the system behaves as if all revenues are delivered directly to the state and are then distributed to the school districts. 
Table 2.1

Distribution of Education Revenue per student Across Districts Relative to Mean District, 1971-1792

\section{Range}

$<.40$

$.4-.5$

$.5-.6$

$.6-.7$

$.7-.8$

$.8-.9$

$.9-1.0$

$1-1.1$

$1.1-1.2$

$1.2-1.3$

$1.3-1.4$

$1.4-1.5$

$1.5-1.6$

$1.6-1.7$

$1.7-1.8$

$1.8-1.9$

$1.9-2$

$>2$
Local

$\begin{array}{cll}\text { Unified } & \text { High } & \text { Elem } \\ .036 & .025 & .044 \\ .021 & .025 & .044 \\ .057 & .050 & .044 \\ .121 & .100 & .110 \\ .171 & .075 & .154 \\ .100 & .250 & .077 \\ .093 & .150 & .143 \\ .071 & .075 & .044 \\ .064 & .075 & .099 \\ .050 & .075 & .033 \\ .043 & .025 & .033 \\ .036 & 0 & 0 \\ .036 & .050 & .055 \\ .043 & 0 & .033 \\ .014 & 0 & .033 \\ .014 & 0 & .033 \\ .007 & 0 & 0 \\ .021 & 0 & .022\end{array}$

$\underline{\text { State \& Local }}$

$\begin{array}{cll}\text { Unified } & \text { High } & \text { Elem } \\ 0 & 0 & 0 \\ 0 & 0 & 0 \\ .014 & 0 & 0 \\ .008 & .025 & .022 \\ .064 & .050 & .055 \\ .278 & .125 & .297 \\ .221 & .350 & .176 \\ .171 & .250 & .176 \\ .114 & .100 & .110 \\ .064 & .075 & .099 \\ .007 & .025 & .033 \\ .029 & 0 & .022 \\ 0 & 0 & 0 \\ .007 & 0 & .011 \\ .014 & 0 & 0 \\ 0 & 0 & 0 \\ .007 & 0 & 0 \\ 0 & 0 & 0\end{array}$

Source: Calculated from figures from Census of Governments, 1972.

The first three columns show the distribution across districts, relative to the mean district, of education revenues per student generated solely by local property taxes. The last three columns show the same information for local and state revenues combined. In both cases the distribution is shown for three types of districts: unified (consisting of both elementary and high schools), High (only high schools) and Elem (only elementary schools). The key piece of information to draw from this table is that even prior to the reforms, the California system involved a substantial amount of redistribution; state aid clearly worked to compress the distribution of spending per student across districts. ${ }^{13}$

${ }^{13}$ The evidence though is only suggestive since the data alone cannot tell us what the distribution would have been had there been no redistribution. 
The combined effects of serrano and Proposition 13 on the distribution and pattern of spending on education in California are dramatic. Table 2.2 shows the distribution of spending per student across districts and across students, relative to their respective means, for the years 1971-72 and 198687.

Table 2.2

Distribution of Education Revenue per student

1971-72

\begin{tabular}{|c|c|c|c|c|c|c|c|c|c|}
\hline & & $\begin{array}{l}\text { Across } \\
\text { to Mean }\end{array}$ & $\begin{array}{l}\text { udents } \\
\text { tudent }\end{array}$ & elati & & $\begin{array}{l}\text { Across I } \\
\text { to Mean }\end{array}$ & $\begin{array}{l}\text { stric } \\
\text { istri }\end{array}$ & Relat: & \\
\hline Range & & Unified & High & Elem & ALL & Unified & High & Elem & ALL \\
\hline$<.75$ & & .01 & .10 & .03 & .01 & .05 & .05 & .04 & .10 \\
\hline .75 & -.9 & .38 & .06 & .31 & .36 & .31 & .15 & .33 & .30 \\
\hline .9 & -1.05 & .19 & .47 & .36 & .25 & .35 & .50 & .33 & .28 \\
\hline 1.05 & -1.20 & .29 & .28 & .18 & .20 & .15 & .20 & .13 & .17 \\
\hline 1.20 & -1.35 & .06 & .06 & .10 & .11 & .07 & .08 & .13 & .09 \\
\hline 1.35 & -1.5 & .03 & .03 & .02 & .04 & .03 & .03 & .02 & .04 \\
\hline$>1.5$ & & .03 & 0 & .01 & .03 & .03 & 0 & .01 & .03 \\
\hline
\end{tabular}

Across students Relative to Mean student

$\begin{array}{lcccccccc}\text { Range } & \text { Unified } & \text { High } & \text { Elem } & \text { ALL } & \text { Unified } & \text { High } & \text { Elem } & \text { ALL } \\ <.75 & & 0 & 0 & 0 & 0 & 0 & 0 & 0 \\ .75-.9 & .11 & .03 & .03 & .16 & .07 & .03 & .02 & .16 \\ .9-1.05 & .60 & .73 & .86 & .55 & .73 & .71 & .87 & .57 \\ 1.05-1.20 & .27 & .19 & .08 & .26 & .16 & .19 & .07 & .21 \\ 1.20-1.35 & .01 & .05 & .02 & .02 & .02 & .07 & .02 & .04 \\ 1.35-1.5 & 0 & 0 & 0 & .01 & .01 & 0 & 0 & .02 \\ >1.5 & .01 & 0 & .02 & 0 & .02 & 0 & .02 & .01\end{array}$


It is fairly obvious that the distribution in 1986-87 is much less spread out than is the one for 1971-72.14 More formally, the coefficient of variation in spending per student was reduced from .23 in 1972 to .11 in 1987 (across all district types). 15

Accompanying the above change in the distribution of educational expenditures was an equally dramatic change in the share of personal income devoted to public primary and secondary education. As Table 2.3 demonstrates, prior to the reforms California's investment share for public primary and secondary education was roughly the same as the US average. After the reform this share dropped on the order of ten to fifteen percent. 16

Table 2.3

Current Expenditure on Education As a Share of Personal Income

$\begin{array}{lllr}\text { Year } & \text { CA } & \text { USA } & \text { CA/USA } \\ 1967 & .036 & .036 & .99 \\ 1969 & .036 & .038 & .95 \\ 1970 & .046 & .041 & 1.12 \\ 1971 & .042 & .043 & .99 \\ 1972 & .039 & .043 & .90 \\ 1974 & .041 & .041 & .99 \\ 1975 & .038 & .042 & .90 \\ 1976 & .044 & .047 & .95 \\ 1981 & .033 & .038 & .87 \\ 1984 & .030 & .037 & .81 \\ 1986 & .033 & .038 & .87 \\ 1987 & .033 & .039 & .85 \\ 1989 & .032 & .038 & .84 \\ 1990 & .035 & .039 & .90 \\ 1991 & .038 & .042 & .90 \\ 1992 & .036 & .042 & .87 \\ 1993 & .035 & .041 & .85\end{array}$

Source: Statistical Abstract of the United States, various.

${ }^{14}$ Although the current system is basically designed to obtain equal spending per student across all districts, there are two reasons why there is still variation across districts. First, elementary and high school students are weighted differently in funding formulas, and hence different student body composistions lead to apparently different levels of per student spending. second, some categorical aid is not included in the revenue limits, e.g. aid to districts with proportionally higher rates of children in families 
To recapitulate, Serrano and Proposition 13 had a quantitatively important effect on equity and on the fraction of total resources that California dedicated to education. The next section of the paper will present a simple model that attempts to make sense of these consequences.

\section{The Model}

As will be seen below, our analysis is consistent with many variants of a human-capital growth model. Nonetheless, to provide context for the analysis that follows it is helpful to discuss one such model. The model sketched below is similar in spirit to that of Loury (1981).

Consider an overlapping generations model with constant population in which individuals live for two periods. Individuals are organized into families, each consisting of one young (first period) and one old (second period) individual. An old individual is endowed with some number of efficiency units of labor which is supplied inelastically. There is an aggregate production technology that is linear in efficiency units of labor. Each old individual has preferences described by a utility function u(c,q), where $c$ is a private consumption good and $q$ is the quality of education obtained by the child, measured in units of the consumption good. A child's quality of education when young influences the number of efficiency units of human capital they are endowed with when old. Young individuals do nothing other than obtain education, and all decisions are made by old individuals.

receiving AFDC.

${ }^{15}$ Similar numbers are obtained for each type of district separately.

${ }^{16}$ We note also that prior to reform, California was spending a similar fraction of its personal income on education as other states with similar per capita incomes such as Connecticut, New Jersey and Maryland. 
Depending upon the technology which maps investment in human capital today (i.e., q) into efficiency units of labor tomorrow, the model may exhibit endogenous growth or may possess a steady state. For our purposes this distinction will not be important and hence we do not further specify these details.

The subsequent analysis examines how different systems used to finance the accumulation of human capital affect both the resources devoted to education and their distribution. Our focus is on how these finance systems affect the decisions made by a particular generation given their distribution of income. Hence, ours is effectively a static analysis. 17 while on the one hand an analysis that traced out the longer run implications of a change in financing rules would be of additional interest, its absence has the advantage of requiring far less structure, some of which is controversial (e.g., the exact mapping from educational resources to future income does not have to be specified). 18 Furthermore, given our interest in the specific experience of education financing in California, the fact that reforms have been in place for roughly fifteen years suggests that it is appropriate to abstract from the potential longer-tern effects of the reform on the distribution of income.

\section{I Basic Assumptions}

The economy is described by an initial income distribution $F(y)$, where $F($.$) is a cumulative distribution function and y$ is income. Reflecting the Us (and Californian) income distribution, we assume $F(\mu)>.5$, i.e. median income is less than mean income, $\mu$. To make this model as simple as possible, we

${ }^{17}$ See Fernandez and Rogerson (1994) for an analysis that does take into account the dynamic aspects of education finance reforms.

${ }^{18}$ See Hanushek (1986) and Heckman et al. (1995) for reviews and critical assessments of this literature. 
assume that individuals have identical preferences over only two goods:

consumption, c, and education, q. Preferences are described by the utility function:

$$
u(c)+v(q)
$$

where $u$ and $v$ are both concave and $u^{\prime}(0)=v^{\prime}(0)=\infty .^{19}$

The amount or quality of education that an individual receives is assumed to be a function solely of spending ( $T$ ) per student (N) which, without loss of generality, we take to be linear, i.e.

$$
\mathrm{q}=\mathrm{T} / \mathrm{N}
$$

Financing systems can involve a mix of financing at the local (i.e. community) and state levels. ${ }^{20}$ In these cases, outcomes are dependent on how families sort themselves into communities. As is standard in much of the local public finance literature, we will assume that individuals sort themselves perfectly into communities, so that each community consists of families that are homogeneous. ${ }^{21}$ This implies that all redistribution is across, rather than within, communities.

We next consider the equilibrium outcomes under two different financing rules. The first is meant to capture essential elements of the pre-serrano environment whereas the second reflects the rules post serrano and proposition 13. In both cases the political economy of the environment is modelled as that corresponding to majority rule. That is, the tax rates, foundation

${ }^{19}$ This utility function should really be interpreted as an indirect utility function that results from combining a utility function over current consumption and the child's future income with a mapping from educational expenditures to future income. The assumption of separability is not key to our analysis. Note also that because there is no uncertainty, we are only assuming that some monotone transformation yields separability.

${ }^{20}$ In general, private funding may also be involved, e.g. private schools. We do not permit that alternative in the analysis that follows, though it is subsequently discussed in section 5 . 
amounts, state funding, etc. are taken to be the outcomes of a system in which individuals can choose the value of the variable via (pair-wise) majority vote.

\subsection{The Pre-Serrano Environment: A Foundation System}

The essence of a foundation system is that all participating districts tax at some minimum level in return for some guaranteed base level of expenditures per student, but there is no restriction on the ability of districts to raise additional revenue through local taxation if they so choose. We model this system in the following manner. We assume that the foundation grant is financed by a proportional tax $\tau$ on income, and that the proceeds are then divided equally across all students. Thus, the relationship between $\mu$, the foundation grant $f$, and the tax rate $\tau$ is given by:

$$
\mathbf{f}=\tau \mu
$$

We also assume that each community $i$ (which therefore corresponds to an individual with income $Y_{i}$ ' may choose to augment the foundation grant through a local proportional tax on income, denoted $t_{i}$. This tax can be thought of as being chosen once the majority vote decision over $\tau$ has occurred. 22 Thus, community i's per student school budget is

$$
q_{i}=f+t_{i} y_{i}
$$

${ }^{21}$ See Hamilton (1975) for an analysis of mechanisms which support perfect separation in equilibrium. See Fernandez and Rogerson (1996) for an analysis of inefficiencies that may arise in a pure local system in which heterogeneous individuals reside within the same community and Durlauf (1995) for a dynamic analysis of the possible poverty traps that can arise.

22 Note that given perfect sorting of individuals across communities it does not matter if local taxation is lump-sum or proportional. 
An individual with income $y_{i}$, therefore, has utility given by

$$
u\left(y_{i}\left(1-\tau-t_{i}(\tau)\right)\right)+v\left(\tau \mu+t_{i}(\tau) y_{i}\right)
$$

where $t_{i}(\tau)$ corresponds to that individual's optimal choice of $t_{i}$ given $\tau$. Thus, $t_{i}(\tau) \geq 0$ is implicitly defined by:

$$
-u^{\prime}\left(y_{i}\left(1-\tau-t_{i}\right)\right) y_{i}+v^{\prime}\left(\tau \mu+t_{i} y_{i}\right) y_{i}+\gamma_{i}=0
$$

where $\gamma_{i}$ is the Lagrange multiplier for the non-negativity constraint on $t_{i}$, and $\gamma_{i} \geq 0, \gamma_{i} t_{i}=0$.

Similarly, this individual's preferred foundation amount and therefore implied preferred tax rate, $\tau_{i}$, is given by maximizing (3.5) with respect to $\tau$ subject to $\tau_{i}, t_{i}\left(\tau_{i}\right) \geq 0$, yielding:

$$
-u^{\prime}\left(y_{i}\left(1-\tau_{i}-t_{i}\left(\tau_{i}\right)\right) y_{i}+v^{\prime}\left(\tau_{i} \mu+t_{i}\left(\tau_{i} y_{i}\right)\right) \mu+\lambda_{i}=0\right.
$$

as the first-order condition, where $\lambda_{i}$ is the Lagrange multiplier for the nonnegativity constraint on $\tau_{i}$, and $\lambda_{i} \geq 0, \lambda_{i}{ }^{\tau}=0$.

It is easy to see that any individual whose income is strictly smaller than $\mu$ will have a preferred foundation tax rate such that her own $t_{i}=0$. Similarly, any individual whose income is strictly greater than $\mu$ would prefer a foundation tax rate of zero and to set $t_{i}$ to finance her entire education. This reflects the redistributional incentives of the foundation system: Individuals whose income is higher than the mean prefer as small a foundation as possible; individuals whose income is below the mean prefer their entire educational expenditures to be financed through the foundation.

Note that the only variable that is assumed to be an outcome of majority vote is $\tau$. Furthermore, utility as expressed in (3.5) is single-peaked in $\tau$. 
This ensures the existence of a majority voting equilibrium. Nonetheless, it is useful to further constrain preferences in order to be able to characterize equilibrium more fully. We next turn to this task.

A natural constraint to impose on preferences is to require that individuals with greater income (but smaller than $\mu$ ) desire to spend additional funds on education through a greater foundation level, i.e. that $\tau_{i}$ be strictly increasing in $y_{i}$ for $Y_{i}<\mu$.

Using the implicit function rule on (3.7) yields, for $y_{i}<\mu$,

$$
\frac{d \tau_{i}}{d y_{i}}=\frac{u^{\prime \prime}\left(y_{i}\left(1-\tau_{i}\right)\right) c_{i}+u^{\prime}\left(y_{i}\left(1-\tau_{i}\right)\right)}{u^{\prime \prime}\left(y_{i}\left(1-\tau_{i}\right)\right) y_{i}^{2}+v^{\prime \prime}\left(\tau_{i} \mu\right) \mu^{2}}
$$

Thus, a sufficient and necessary condition to obtain $\tau_{i}$ increasing with $y_{i}$ is:

$$
u^{\prime \prime} c+u^{\prime}<0
$$

which we henceforth impose. ${ }^{23}$

It follows that the decisive voter in a majority vote system will be $\tilde{y}_{f}$ such that:

$$
F(\mu)-F\left(\tilde{Y}_{f}\right)=.5
$$

since all individuals with income greater than $\mu$ have a preferred tax rate of zero, and all those with income smaller than $\tilde{y}_{f}$ have a preferred tax rate smaller than the $\tau$ preferred by $\tilde{Y}_{f}$.

Lastly, note that an implication of (3.9) and (3.10) is that individuals with income strictly greater than $\mu$ will wish to impose a positive $t_{i}$, that is, to "top-up" the amount granted by the foundation. To see this, note that

${ }^{23}$ This condition is often imposed in multi-community models without perfect sorting. See Westhoff (1977). 
the equilibrium $\tau, \tau_{f}$, is strictly positive and is the preferred tax rate of an individual whose income is $\tilde{y}<\mu$. Thus, for this individual, $t_{i}=0$ and, by (3.7), $u^{\prime} \tilde{y}_{f}=v^{\prime} \mu$. Consequently, if an individual with income $y_{i}>\mu$ sets $t_{i}$ equal to zero, $v^{\prime}\left(\tau_{f} \mu\right)=u^{\prime}\left(\tilde{y}_{f}\left(1-\tau_{f}\right)\right)\left(\tilde{y}_{f}\right) / \mu$ which, by $(3.9)$ is strictly greater than $u^{\prime}\left(y_{i}\left(1-\tau_{f}\right)\right)$. Thus, by (3.6), this individual will set $t_{i}$ positive at an optimum. In fact, all individuals with income strictly greater than $y_{T}$ will spend more on education than the foundation amount, where $Y_{T}$ is implicitly defined by:

$$
u^{\prime}\left(y_{T}\left(1-\tau_{f}\right)\right)=u^{\prime}\left(\tilde{y}_{f}\left(1-\tau_{f}\right)\right) \tilde{y}_{f} / \mu
$$

We are now set to characterize equilibrium under a foundation system.

The decisive voter under this system, $\tilde{y}_{f}$, is implicitly defined by (3.10), and imposes a tax rate $\tau_{f}$ as given by (3.7) (with $\lambda_{i}=0$ ) for $y=\tilde{y}_{f}$. All individuals with $y_{i}>y_{T}$ top up their educational expenditures by an amount $t_{i} Y_{i}$ where $t_{i}$ satisfies $(3.6)$ (and $\gamma_{i}=0$ ). Individuals with $y_{i} \leq y_{T}$ spend only the foundation amount $f=\tau_{f} \mu$ on education, setting $t_{i}=0$. We next turn to a comparison of this system with that implied by the post serrano and Proposition 13 environment.

3.3 The Post Serrano and Proposition 13 Environment: A State System As described in section 2, the effect of Serrano and Proposition 13 was to take away districts' ability to make their own school-financing decisions and to replace this with state funding. Thus, a state system was created which guaranteed that virtually all districts spent the same amount (per student) on education. As before, we assume that this amount is both determined and financed by a state income tax, $\hat{t}$, thus guaranteeing each 
district

$$
q=\hat{t} \mu
$$

funds per student and taxing each individual at the rate $\hat{t}$. Note that unlike in the foundation system, however, districts are not able to supplement state spending with local spending--the legacy of proposition 13.

To trace out the effect of different tax rates on individual welfare, we can rewrite utility under the state system as:

$$
u\left(y_{i}(1-\hat{t})\right)+v(\hat{t} \mu)
$$

Maximizing (3.13) with respect to $\hat{t}$ yields the preferred state tax rate, $\hat{t}_{i}$, for an individual with income $y_{i}$, defined implicitly by

$$
-u^{\prime}\left(y_{i}\left(1-\hat{t}_{i}\right)\right) y_{i}+v^{\prime}\left(\hat{t}_{i}^{\mu} \mu=0\right.
$$

Note that (3.14) is identical to (3.7) (with $t_{i}=0$ and $\lambda_{i}=0$ ). But, this implies that the individuals with $Y_{i}<\mu$ have the same preferred tax rate under both systems, i.e. $\tau_{i}=\hat{t}_{i}$ for $y_{i}<\mu$. The same is not true, however, for individuals whose income is strictly greater than $\mu$ since under a foundation system they prefer to set the tax rate equal to zero whereas under a state system they prefer a positive tax rate. Furthermore, the fact that (3.14) is identical to (3.7) implies that preferred tax rates as a function of income are given by (3.8) for all $Y_{i}$, and therefore, given (3.9), that $\hat{t}_{i}$ is increasing in $Y_{i}$.

The above dichotomy can be easily understood by noting that under the foundation system individuals had the alternative of funding their educational expenditures out of mean income and/or out of individual income. of course, 
any individual whose income is greater than the mean prefers to fund out of individual income and the opposite for those whose income is below the mean. Under a state system, however, individuals do not have the option of funding education out of personal (or district level) income. Consequently, while preferred tax rates for individuals whose income is below the mean remains unchanged, individuals with high income now want a positive state level tax. It is now easy to describe equilibrium outcomes under the state system. Since $\hat{t}_{i}$ is increasing in $y_{i}$, the decisive voter in this system is $\hat{y}_{s}$ such that:

$$
F\left(\hat{y}_{s}\right)=.5
$$

Thus, the equilibrium state tax rate, $\hat{t}_{S}$, is given by (3.14) for $y_{i}=\hat{y}_{S}$ and all individuals have equal educational expenditures of $\hat{t}_{\mathbf{s}}{ }^{\mu}$. 3.4 A Comparison of the Two Systems

Two important concerns in evaluating the state relative to the foundation system are: (i) which system delivers greater resources to education, and (ii) whether there is an important tradeoff between the distribution of resources and total resources.

A first comparison to note is that while under both systems the decisive voter is an individual whose income is below the mean, that income level is smallex under the foundation system than under the state system, i.e. $\tilde{Y}_{\mathrm{f}}<\hat{Y}_{\mathbf{S}}$. This follows simply from the fact that under a foundation system the preferred tax rate is zero for individuals whose income is above the mean, whereas it is positive and increasing in income under the state system. Thus, while under the foundation system the preferences of the poorest and richest individuals are relatively close, under the state system they are relatively far apart. 
From the above we can conclude that the income tax rate under the state system will be higher than the foundation tax rate. This implies that in the absence of any topping-up in the foundation system, total educational expenditures in the state system would exceed that in the foundation system. Consequently, independently of which system ends up with higher spending on education, under the state system all individuals with income lower than the median will have higher spending per student than under the foundation system. Thus, even if the foundation system delivers higher total spending, it may come at the expense of much lower spending for lower income individuals. Given our conclusion that the state system delivers greater resources to education for all individuals with income below the mean (in fact, to all individuals who are topping up by less than the difference between the state spending level and the foundation grant level), it is important to ascertain whether indeed the foundation system delivers greater total resources to education and what the tradeoff is in terms of spending for lower income individuals. To see, however, that the foundation system may in fact do well under the first criterion and actually not badly under the second, it is instructive to consider the extreme case in which $u^{\prime \prime} c+u^{\prime}=0$ (i.e. log preferences over consumption). With these preferences all individuals with income below the mean have the same preferred tax rate. Thus, the equilibrium tax rate will be the same under both systems, i.e. $\tau_{f}=\hat{t}_{s}$. Note, however, that under the foundation system individuals can top up and, it is easy to show that for these preferences all individuals with income greater than the mean will do so and those with income below the mean will spend only the foundation grant. Under the state system, of course, individuals are not able to top up. Consequently, for these preferences spending is unambiguously higher in the foundation system and not at the expense of lower spending for 
low income individuals. While this case is an extreme, it is instructive since, as our next section will argue, the data suggests that preferences are close to this description.

An important point to note here is that the trade off between total resources dedicated to education and equity is in any case not a simple one across systems. Consideration of a third system--a pure local system--is revealing for these purposes. In a pure local system, funds are raised via taxation at the local level and there is no redistribution across districts. Ceteris paribus, therefore, this system will lead to greater inequality in educational spending across individuals without necessarily delivering greater total spending. Thus, in general, although we can rank the systems with respect to the variance in educational expenditures that would be observed (namely, in decreasing order, state then foundation then local) we cannot rank these three systems with respect to total spending nor discuss the magnitude of the possible tradeoffs without knowing more about preferences and the income distribution.

\section{The Quantitative Effects of Reform}

In this section we use data to restrict the model of the previous section and explore the implications of the restricted model for California's education finance reform. This requires that we specify both the income distribution and explicit functional forms for preferences.

\subsection{Functional Forms}

The model has adults making decisions over consumption and education for one period. Hence, a more appropriate income distribution for our purposes is 
the distribution of lifetime income, rather than the income distribution for a particular year. Fullerton and Rogers (1993) estimate the distribution of lifetime household income for the US using data from the PSID for the years 1970-1987. They compute mean lifetime income for each decile (subdividing the lowest and highest deciles each into two groups) for both pretax income as well as income net of taxes and transfers. We used both of these distributions in our analysis, but found that the results did not differ in any significant way. Consequently, we only report results for the case of income net of taxes and transfers. Table 4.1 displays the income distribution. 24

$\begin{array}{cc}\text { Table } 4.1 \text { Lifetime Income Distribution } \\ \text { Percentile } \\ \\ \text { (000's of } 1986 \text { dollars) } \\ 0-2 & 217 \\ 2-10 & 355 \\ 10-20 & 433 \\ 20-30 & 515 \\ 30-40 & 565 \\ 40-50 & 665 \\ 50-60 & 735 \\ 60-70 & 814 \\ 70-80 & 911 \\ 80-90 & 1028 \\ 90-98 & 1305 \\ 98-100 & 1734\end{array}$

Source: Fullerton and Rogers (1993)

For some issues of interest, it is desirable to employ a less coarse distribution of income. There are many ways in which such a distribution can be produced. Here we use a lognormal distribution whose parameters are chosen by selecting those which do the best job of reproducing the distribution of

${ }^{24}$ Ideally we would use the Californian lifetime household income distribution, but this is not available. 
mean income for the deciles depicted in the above table. Our criterion of best is the sum of absolute deviations of the mean incomes.

As a starting point we consider preferences given by the functional form:

$$
u(c)+v(q)=\frac{c^{\alpha}}{\alpha}+A \frac{q^{\gamma}}{\gamma} \quad A>0
$$

Condition (3.9) is satisfied if and only if $\alpha<0$. Just to indicate the range of possibilities that this specification permits, the table below shows the results that obtain for selected values of $\alpha$ and $\gamma$. In each case $A$ is chosen so that total spending in the foundation system is .048 of total income, which is the corresponding ratio for state plus local educational revenues in California in 1971.25 We use the income distribution of Table 4.1.

Table 4.2

Comparison of state Versus Foundation System, selected Parameter Values

$\begin{array}{lcc}\alpha & \gamma & \left(Q_{\mathbf{S}}-Q_{\mathrm{f}}\right) / Q_{\mathrm{f}} \\ -0.01 & -5.0 & -.02 \\ -1.0 & -2.0 & -.04 \\ -0.01 & -0.01 & -.13 \\ -2.0 & -0.50 & -.24 \\ -2.0 & -0.01 & -.41\end{array}$

Table 4.2 shows that for a given income distribution the model predicts a drop in educational spending as small as $2 \%$ or as large as $40 \%$ depending upon parameter values. Obviously, obtaining sharper predictions requires additional restrictions on preferences. Somewhat surprisingly, we show that a simple restriction implied by longer-run evidence greatly reduces the model's

${ }^{25}$ Here we use revenues rather than current expenditures since while the latter is more comparable across states, the former is a more comprehensive measure of total resources. 
predicted responses, even without assigning values for all parameters. Given the wide range of possible outcomes suggested by Table 4.2 , this is a very useful finding.

The restriction that we impose arises from the finding that over the long run, educational expenditures and personal income grow at (approximately) the same rate. To motivate this finding we consider data for the us over the period 1960-1993. Real personal income (Y) and real expenditures for public primary and secondary education (Q) are both obtained by using the CPI to deflate nominal quantities. We run the two following regressions:

$$
\begin{aligned}
& \log \left(Q_{t}\right)=a+b \log \left(Y_{t}\right)+\epsilon_{t} \\
& Q_{t} / Y_{t}=a+b t+\epsilon_{t}
\end{aligned}
$$

The results are displayed in Table 4.3

$$
\text { Table } 4.3
$$

Regression Results for Equations (4.2) and (4.3)

(standard errors in parentheses)

$\begin{array}{cccc} & \mathrm{a} & \mathrm{b} & \mathrm{R}^{2} \\ \text { eq }(4.2) & -3.14 & 1.02 & .92 \\ & (.18) & (.06) & \\ \text { eq (4.3) } & .0461 & -.00002 & .0021 \\ & (.0015) & (.00007) & \end{array}$

\footnotetext{
Both sets of results support the finding that there is no sign of a secular trend in the fraction of personal income going to public primary and secondary education. 26
}

${ }^{26}$ In addition to the secular trend in personal income there has also been a decrease in fertility rates over this period which has not been taken into consideration in the above regressions. Fernandez and Rogerson (1995) using a panel data set for US states over the period 1971-1992 show, however, that the same conclusion holds when this is accounted for. 
The finding that personal income and educational expenditures grow at the same rate can be used to restrict the set of allowable preferences. In particular, it is straightforward to show for foundation, state and local systems of finance that a proportionate scaling of the income distribution leads to the same proportional increase in educational expenditures if and only if preferences are homothetic, i.e. the slope of an indifference curve in c-q space is a function only of the ratio of $c$ to $q$. Given a restriction to homothetic preferences, the natural class of utility functions to consider is that of constant elasticity of substitution (and monotone transformations). This requirement is equivalent to imposing $\alpha=\gamma$ in the preferences displayed in equation (4.1), and in what follows we restrict our attention to this class.

It is useful to determine the equilibrium values of the variables for the class of preferences discussed above. Using equation (3.7) and (3.14), it is easy to show that:

$$
\begin{aligned}
& \hat{\tau}_{\mathrm{f}}=\left[\mathrm{A}^{1 / \beta}\left(\mu / \hat{Y}_{\mathrm{f}}\right) \alpha / \beta+1\right]^{-1} \\
& \hat{t}_{\mathrm{s}}=\left[\mathrm{A}^{1 / \beta}\left(\mu / \hat{\mathrm{Y}}_{\mathrm{s}}\right)^{\alpha / \beta}+1\right]^{-1}
\end{aligned}
$$

where $\beta=\alpha-1$. An individual with income $y_{i}$ tops up her educational expenditures under the foundation system by an amount:

$$
t_{i} y_{i}=\max \left\{0, \tau_{f} A^{1 / \beta}\left[\left(\mu / \tilde{y}_{f}\right)^{\alpha / \beta} y_{i}-\mu\right] /\left(1+A^{1 / \beta}\right)\right\}
$$

So, for our CES preferences we can note from the above that (i) the amount by which individuals top up is linear in income (for $y_{i}>y_{T}$ ), and (ii) as $\alpha$ increases, the number of individuals that top up falls, i.e., $Y_{T}$ is increasing in $\alpha$. 
4.2 Impact on Total Expenditures on Education

Table 4.4 shows the predicted effects of the Californian reform for various settings of $\alpha=\gamma$. As before, the constant $A$ is chosen so that the fraction of income devoted to education in the foundation system is equal to .048

\begin{tabular}{rrrrr}
\multicolumn{5}{c}{$\begin{array}{c}\text { Table } 4.4 \\
\text { Comparison of Foundation vs. State system } \\
\text { Results for CES Utility Function }\end{array}$} \\
$\alpha$ & $\left(Q_{s}-Q_{f}\right) / Q_{f}$ & $\left(Q_{f}-f\right) / Q_{f}$ & $Q_{s} / f$ & $\sigma / \mu$ \\
-5 & -.08 & .45 & 1.67 & .38 \\
-3 & -.08 & .42 & 1.59 & .38 \\
-1 & -.08 & .32 & 1.35 & .35 \\
-.5 & -.09 & .25 & 1.21 & .32 \\
-.3 & -.10 & .22 & 1.15 & .29 \\
-.2 & -.11 & .19 & 1.10 & .28 \\
-.1 & -.12 & .16 & 1.05 & .26 \\
-.01 & -.13 & .13 & 1.00 & .23
\end{tabular}

The third column, headed $\left(Q_{f}-f\right) / Q_{f}$, shows the fraction of total expenditures that are accounted for by spending over and above the foundation amount $f$. The next column headed $Q_{\mathbf{S}} / f$ shows the amount by which total spending in a state system exceeds the foundation grant level. Equivalently, it is the ratio of the tax rate under the state system to the foundation tax rate. The last column headed $\sigma / \mu$ shows the coefficient of variation for the distribution of spending per student across students. As can be seen, under a CES specification, the model predicts a drop of educational spending roughly on the order of $10 \%$, with a range between 8 and $13 \%$ depending upon the exact value of $\alpha$.

A clear pattern emerges as $\alpha$ increases: the effect of the reform on total expenditures becomes greater, the coefficient of variation decreases, the fraction of spending accounted for by the foundation grant alone increases, and the level of state spending relative to the foundation grant decreases. 
Note that the above is more than a comparative statics exercise with respect to $\alpha$ since in the background $A$ is changing so as to keep the fraction of income spent on education constant under the foundation system. Nonetheless, from the results in the previous subsection, it is clear that as $\alpha$ increases the number of individuals that top up decreases.

Recalling the discussion in section 3.3, there are two opposing effects on total expenditures associated with a move from a foundation system to a state system. On the one hand, spending decreases because districts cannot supplement state aid (the importance of this amount to total spending under the foundation system can be seen in column 3), and on the other hand, spending increases relative to the foundation grant level because the decisive voter in the state system prefers a greater tax rate (column 4). As the table shows, both of these effects become smaller as $\alpha$ increases, but the size of the second effect decreases at a faster rate, thus leading to the overall pattern of a greater decrease in total spending as $\alpha$ increases. Hence, rather paradoxically, it is in those economies in which the amount of topping-up is greatest that the move to a state system results in the smallest drop in total spending.

Given the abstract nature of the model and the relative tightness of the range obtained in Table 4.4, we take our findings to imply that the analysis predicts a decrease of total spending on the order of $10 \%$. In what follows we attempt to say something about reasonable values of $\alpha$, by comparing the distribution of expenditures across students implied by the model with the corresponding distribution found in the data for California in 1971-1972.27

27 It should be noted that there is nothing particularly special about the '71-'72 distribution--the '67-'68 is similar and could have been used instead. 
For this part of the analysis we now use the income distribution with a finer grid, generated using the procedure described previously. Table 4.5 shows, for several values of $\alpha$, the implied distribution of spending per student across students relative to mean spending as well as the distribution for three different school data sets for California in 1971-72: unified districts, high school districts and elementary districts. In each case only districts with more than 3000 students are included. 28

Table 4.5

Distribution of students by spending per student, Relative to Mean

\begin{tabular}{|c|c|c|c|c|c|c|c|c|}
\hline \multirow[b]{2}{*}{ Range } & \multicolumn{4}{|c|}{ Model } & \multicolumn{4}{|c|}{ Data } \\
\hline & $\alpha=-1.25$ & $\alpha=-.35$ & $\alpha=-.25$ & $\alpha=-.15$ & $\alpha=-.05$ & Unified & High & Elem \\
\hline$<.7$ & .24 & 0 & 0 & 0 & 0 & .01 & 0 & .02 \\
\hline $.7-.8$ & .13 & .42 & 0 & 0 & 0 & .03 & .11 & .03 \\
\hline $.8-.9$ & .13 & .12 & .55 & .57 & .59 & .22 & .04 & .29 \\
\hline $.9-1.0$ & .11 & .11 & .10 & .10 & .11 & .33 & .33 & .21 \\
\hline $1.0-1.1$ & .10 & .09 & .09 & .09 & .08 & .21 & .32 & .19 \\
\hline $1.1-1.2$ & .07 & .07 & .07 & .07 & .06 & .08 & .11 & .13 \\
\hline $1.2-1.3$ & .06 & .05 & .05 & .05 & .05 & .06 & .03 & .07 \\
\hline $1.3-1.4$ & .05 & .04 & .04 & .03 & .03 & .01 & .06 & .03 \\
\hline $1.4-1.5$ & .03 & .03 & .03 & .03 & .02 & .02 & .00 & .02 \\
\hline $1.5-1.6$ & .03 & .02 & .02 & .02 & .02 & 0 & 0 & 0 \\
\hline $1.6-1.7$ & .02 & .01 & .01 & .01 & .01 & 0 & 0 & .01 \\
\hline $1.7-1.8$ & .01 & .01 & .01 & .01 & .01 & .01 & 0 & 0 \\
\hline $1.8-1.9$ & .01 & .01 & .01 & .01 & .01 & 0 & 0 & 0 \\
\hline $1.9-2.0$ & .01 & .01 & .01 & .00 & .00 & 0 & 0 & 0 \\
\hline$>2.0$ & .02 & .01 & .01 & .01 & .01 & 0 & 0 & 0 \\
\hline$\sigma / \mu$ & .34 & .29 & .27 & .26 & .24 & .18 & .15 & .17 \\
\hline
\end{tabular}

Source: Calculations for data based on 1972 Census of Governments.

The clearest discrepancy between the model and the actual data is the greater concentration of students at the foundation level implied by the model. This is not very surprising; although the model predicts a mass point at the foundation grant level of spending, in reality, state aid is delivered

${ }^{28}$ The data for unified districts does not include the district of Los Angeles, since the reported number of students for this district seems to be incorrect. 
through additional channels as well. While the data does not show the degree of concentration predicted by the simple model, the data does show a significant amount of bunching at the lower end of the distribution, e.g. 55: of the students fall within the range .8-1.0 for the unified school systems. We conclude that for $\alpha$ close to zero, the predicted distributions are not wildly at odds with those in the data.

As $\alpha$ is varied from -1.25 to -.05 the most important difference that occurs is that the level of the foundation grant increases and the dispersion of individuals in the lower end of the distribution falls, resulting in a lower coefficient of variation. Since in the data the concentration occurs in the range .8-1.0, this suggests that values of $\alpha$ closer to zero will provide a better match with the data. A comparison of the coefficient of variation for the range of $\alpha^{\prime}$ s depicted in Table 4.5 with the actual data also suggests a value of $\alpha$ close to zero. In an attempt to say which $\alpha$ best "matches" the observed distribution we find the value of $\alpha$ which minimizes the sum of absolute deviations from the actual distribution for unified districts. This occurred at $\alpha=-.25$, although as can be seen in the table, there is not a great deal of difference between the distributions for $\alpha$ between -.25 and $\alpha=-.05 .29$ Although our analysis has focused on the change in total spending, the reform also changed the distribution of spending, as shown previously in Table 2.2. One way to think about the distribution of gains and losses is to first assume that total spending had remained constant and had simply been distributed equally across districts. From the last three columns in Table 4.5, one can read off that in this case, among students in unified districts,

${ }^{29}$ The same exercise carried out using the decile distribution of Table 4.1 resulted in $\alpha=-.2$. Using the elementary or high school distributions instead did not have much effect on this outcome. 
for example, $26 \%$ of all students would experience an increase in excess of 10\%, whereas $18 \%$ percent of all students experience a decrease of more than 10\%. Next, taking into account that along with equalized spending there was also a substantial drop in total spending, consider the impact of a drop of 10\%. Now, it is only those students whose spending was less than .8 of mean spending that gain in excess of $10 \%$, while all students initially above mean spending suffer a loss of greater than $10 \%$. Hence, among students in unified districts only $4 \%$ have gains in excess of $10 \%$ whereas $39 \%$ have losses in excess of $10 \%$. We conclude from this that it is likely that the reform led to significant gains in the level of expenditures for only a very small fraction of the population, and significant losses for a substantial fraction.

A similar exercise can be carried out for the model simulations. Given that the model predicts greater concentration at the lower part of the distribution than is found in the actual data, the distribution of gains is somewhat more concentrated as well. For the case where $\alpha=-.25$, for example, $55 \%$ of the students experience a net gain of $6 \%$. Nobody gains in excess of this amount, and $35 \%$ of the students experience a loss in excess of $10 \%$.

\section{Alternative Explanations}

It is of interest to contrast our explanation for the drop in expenditures in California with those that have been proposed elsewhere. We are aware of three alternative explanations. The first, as exposited in Rubinfeld (1995), suggests that voters dislike centralized systems and therefore reduce their support for services if their provision becomes more centralized. While our work does not say anything about the merits of this 
explanation, it does indicate that one need not rely on placing "non-standard" items into preferences to account for the fall in spending. 30

A second explanation, (see, for example, Downes and Schoeman (1992)), is that the reforms of the $1970^{\prime} \mathrm{s}$ lead to increased enrollment in private education by children of wealthier families, thus leading to decreased support for public education. While this explanation is plausible qualitatively, we argue that this effect is not large enough quantitatively, at least in the context of a simple political economy model, to be the dominant factor. Central to our argument is the fact that only an additional $3 \%$ of all students chose private school between 1970 and 1990 (see Downes and Schoeman for details). In a majority voting model, this increase in private school enrollment affects spending on public education in two ways. First, the tax base per student in public education increases. This typically leads to increased spending per pupil, so that the net effect of this change is presumably less than three percent. Second, there is a change in the identity of the decisive voter, since those families with children in private schools no longer desire positive tax rates to support public education. While in general there may be problems with existence of a majority voting equilibrium in this setting because of non single-peaked preferences (see Epple and Romano (1993) and Glomm and Ravikumar (1996) for a treatment of this issue), we can carry out a natural exercise to gauge the effects of increased enrollment in private education on spending in a state system.

We assume that an exogenous three percent of families from the upper part of the income distribution send their children to private school. Preferred

${ }^{30}$ Though, of course, preferences need not be non-standard to explain why individuals may prefer to avoid centralized systems if these are less efficient. See, for example, Hoxby (1995)) for some evidence on this question. 
tax rates for these individuals in our model, therefore, are zero. This shifts the income associated with the decisive voter down accordingly. Since we are interested solely in the magnitude of the change in spending that this change in decisive voter would generate, we compute the change in funding that would result within the context of a state system.

Employing the lognormal distribution used to generate Table 4.6 , and given our restriction to CES preferences, we find that the magnitude of the effects associated with the change in decisive voter are relatively small. For our best match value of $\alpha=-.25$ we find a decrease in the tax rate equal to 1.15\%, whereas for $\alpha=-1$ and $\alpha=-3$ the decreases in tax rates are $3 \frac{8}{\%}$ and $4.5 \%$ respectively. Expenditures on public education, of course, decrease by the same percentage as the tax rate. While our calculations above suggest that the effects can be sizeable for $\alpha$ sufficiently negative, our analysis indicates that reasonable values of $\alpha$ are certainly greater than -1 and more likely close to zero. Thus, although this effect may not be insignificant, we conclude that it is not likely that the increased enrollment in private education was the dominant factor in the decline in educational spending.

The third explanation, put forward by Silva and Sonstelie (1995) is most similar in spirit to ours since they too offer a political economy interpretation of the consequences of switching finance systems. They, however, interpret the drop in spending as resulting from a reform of a pure local system to a pure state system. Using estimates of education demand functions, they find that their model can also explain a drop in spending of about ten percent.

Although we are in agreement with their general political economy approach to interpret what occurred in California, there are two key differences between their analysis and ours: the interpretation of the 
prereform system, and the procedure used to restrict preferences. With regard to the first matter, we have shown that the prereform system did involve a substantial amount of redistribution across districts and hence that it should not be viewed as a pure local system. With regard to the second matter, whereas we use long-run properties to restrict preferences, they estimate a demand function from a cross-section regression involving US states. There are two problems with this procedure. First, it implicitly assumes that each state has a pure local system in place. This is certainly not the case. Second, it does not distinguish between permanent and transitory components in income fluctuations. As a result, their estimates are not consistent with the longer run properties of educational spending, as evidenced by the instability of parameter estimates based on cross-section regressions carried out for different years. 31

The conjunction of these two differences is very significant. For, as we next go on to argue, if one takes a local system and uses the parameter estimates suggested by the data, then California's education finance reform would produce a relatively small effect on spending. In particular, using the income distribution described in Table 4.1 and a pure local finance model (i.e. $\tau=0$ and each income group sets its $t_{i}$ optimally) then setting $\alpha=-.25$ yields a drop in spending of $2 \%$. For $\alpha$ equal to zero, the model predicts no drop in spending (though of course a very different distribution of that spending) due to a move to a state finance system, and if $\alpha=-1$, the decrease is $5 \frac{8}{2}$. So, even by setting $\alpha$ significantly smaller than our best match value, this reform would produce at most half of the fall that our model predicts.

${ }^{31}$ In fact, the functional form that they used for their educational demand function is not consistent with the long run facts for income and spending for any parameter values. 


\section{Conclusion}

In this paper we argue that California's drop in public education spending relative to the rest of the US can be understood using a simple political economy model of public finance. From this perspective, a move from a foundation system to a pure state system entails two key opposing effects. On the one hand, wealthier districts can no longer supplement state aid, thereby leading to lower spending. On the other hand, precisely because wealthier districts cannot supplement state payments, they desire a greater amount of state aid--in particular, greater than the foundation grant level obtained under the foundation system. Absent any restrictions on preferences, the range of predicted changes in education spending is very large. We show that a simple restriction implied by long run considerations greatly restricts the range of predicted outcomes. We conclude that a simple political economy interpretation of the incentives introduced by the change in financing systems can account for the bulk of California's drop in spending.

Though our analysis has been restricted to California, we note two pieces of supporting evidence for the view that state systems may lead to lower levels of resources. The first is the case of Hawaii. Hawaii has a pure state sytem, and as seen in Table 1.1, also has an investment share very similar to California. Second, the state of Washington also moved much closer to a state system as a result of court rulings, and likewise experienced a drop in its investment share of roughly $15 \%$ relative to the us between 1971 and 1992 .

We close with a few cautions about interpreting our results. First, since our analysis found that the switch from a foundation to pure state system of financing accounts for a decrease in total education spending on the 
order of ten percent, one may be tempted to take this as evidence of a negative trade-off between equity and resources devoted to education. As we have emphasized, however, this simple trade-off does not exist. We showed that while the reform greatly increased equity in educational expenditures across students, it did so largely by decreasing spending in wealthy districts, with increases only for students in extremely poor districts. Furthermore, if we were to consider a move to the other extreme--i.e. a move to a pure local system of financing--the falsity of the conclusion becomes evident. In particular, using the same income distribution as in our prior analysis, our model predicts that had California instituted a reform to a pure local system, this would have occasioned a drop in spending of $8.5 \%$ for $\alpha=-$ .25, $13 \%$ for $\alpha=-.001$, and $5 \%$ for $\alpha=-1$. In all cases the coefficient of variation for the distribution of per student expenditures would equal .41 . In short, for $\alpha$ close to zero, a move to a pure local system would have led to a decrease in expenditures on the same order of magnitude as the move to a pure state system, while at the same time resulting in a much greater level of inequality.

A second and related point to keep in mind is that this paper does not trace out the longer term implications of California's drop in educational expenditures. In general, it would be necessary to know both how changes in the level and distribution of expenditures affect the income distribution and how, in turn, the latter affects the growth rate of the economy. ${ }^{2}$ Thus, it is possible that there are efficiency gains associated with changes in the

${ }^{32}$ There are a few papers that attempt to examine some of the theoretical implications of different income distributions on growth, for example, Galor and Zeira (1993) and Banerjee and Newman (1993). 
distribution of resources across students which can offset the losses associated with decreased total spending. 


\section{References}

Banerjee, A. and Newman, A., Occupational Choice and the Process of Development," Journal of Political Economy 101 (1993), 274-298.

Benabou, R., "Heterogeneity, stratification, and Growth, "forthcoming, American Economic Review, 1996.

Brown, L, Ginsburg, A., Killalea, J., Rosthal, R., and Tron, E., "School Finance Reform in the seventies: Achievements and Failures," Journal of Education Finance 4 (1978), 195-212.

Downes, T.,"Evaluating the Impact of School Finance Reform on the Provision of Public Education: The California Case," National Tax Journal 45 (1992), 405419.

Downes, T. and Schoeman, D., "School Financing Reform and Private School Enrollment: Evidence from California," mimeo, Northwestern University, 1992.

Durlauf, S., "A Theory of Persistent Income Inequality," Journal of Economic Growth, forthcoming, 1996.

Epple, D. and Romano, R., "Competition Between Private and Public Schools, Vouchers and Peer Group Effects," mimeo, 1993.

Fernandez, R. and Rogerson, R., "Income Distribution, Communities, and the Quality of Public Education,", forthcoming, Quarterly Journal of Economics, 1996 .

"Public Education and Income Distribution: A Quantitative Evaluation of Education Finance Reform,", National Bureau of Economic Research Working Paper, 1994.

"The Determinants of Public Education Expenditures: Evidence

from the states, 1971-1992," mimeo, 1995.

Fullerton, D., and Rogers, D., who Bears the Lifetime Tax Burden?, The Brookings Institution, Washington D.C., 1993.

Galor, O. and Zeira, J., "Income Distribution and Macroeconomics, "Review of Economic studies $60(1993), 35-52$.

Glomm, G., and Ravikumar, B., "Opting out of Publicly Provided Services," forthcoming, Social Choice and Welfare, 1996.

Hamilton, B.,"Zoning and Property Taxation in a system of Local Governments," Urban Studies 12 (1975), 205-211.

Hanushek, E., "The Economics of Schooling: Production and Efficiency in Public Schools," Journal of Economic Literature 24 (1986), 1141-1177.

Heckman, J., Layne-Farrar, A. and Todd, P., "Does Measured School Quality Really Matter," mimeo, (1995). 
Hoxby C., "Do Private Schoqls Provide Competition for Public Schools," mimeo, Harvard University, 1995.

Inman, R., "Optimal Fiscal Reform of Metropolitan Schools: Some Simulation Results," American Economic Review 68 (1978), 107-122.

Krusell, P., Quadrini, and Rios-Rull, V., "Are Consumption Taxes Really Better than Income Taxes," Journal of Monetary Economics, forthcoming, 1996.

Loury, G., "Intergenerational Transfers and the Distribution of Earnings," Econometrica 44 (1981), 843-867.

Lucas, R., "Supply-Side Economics: An Analytical Review," Oxford Economic Papers 42 (1990), 293-316.

O'sullivan, A., Sexton. T., Sheffrin, S., property taxes and tax revolts, Cambridge University Press, 1995.

Persson, T. and Tabellini, G., "Fiscal Federalism," mimeo, 1993.

Picus, L., "Cadillacs or Chevrolets?: The Evolution of state Control over School Finance in California," Journal of Education Finance 17 (1991), 33-59.

Rubinfeld, D., "California Fiscal Federalism: A School Finance Perspective," mimeo, University of California at Berkeley, 1995.

Silva, F., and Sonstelie, J., "Did Serrano Cause a Decline in School Spending?," National Tax Journal 48 (1995), 199-215.

Tiebout, C., "A Pure Theory of Local Expenditures," Journal of Political Economy $65(1956), 416-24$.

Westhoff, F., "Existence of Equilibria in Economies with a Local Public Good," Journal of Economic Theory 14 (1977), 84-112. 